\title{
With or Without U? Testing the Hypothesis of an Inverted U-Shaped Union Membership-Age Relationship
}

\author{
Claus Schnabel' \& Joachim Wagner ${ }^{2}$
}

\begin{abstract}
In this note, we apply a new test by Lind and Mehlum (2010), casting doubt on the claim proposed by Blanchflower (2007) that the probability of unionisation follows an inverted U-shaped pattern in age with a maximum in the mid- to late 40s. With this new test for an inverted U-shaped pattern, which has not been applied to the age-membership nexus before, and by constructing exact confidence intervals for the maximum value, we demonstrate that - at least with respect to West Germany Blanchflower's hypothesis does not hold. Our findings suggest that more definitive evidence is needed before the existence of international unionisation-age patterns can be taken for granted.
\end{abstract}

KEY WORDS: $\quad$ unionisation, age, inverted U-shape, Germany

JEL Classification: J51

${ }^{1}$ Friedrich-Alexander-Universität Erlangen-Nürnberg, Germany, ${ }^{2}$ Leuphana University Lueneburg, Germany

\section{Motivation}

Lind and Mehlum (2010) showed in a recent paper that statistically significant regression coefficients of a variable and its squared term that have opposite signs, plus a computed extreme value based on these estimated coefficients that lies inside the data range, are only necessary but not sufficient to proof the existence of a Ushaped (or inverted U-shaped) relationship. Specifically, Lind and Mehlum (2010, p. 110) argue "that this criterion is too weak. The problem arises when the true relationship is convex but monotone over relevant data values. A quadratic specification may then erroneously yield an extreme point and hence a U shape." They note that standard testing methodology is no longer suitable for the U-shape test of the composite null hypothesis that

Corespondence concerning this article should be addressed to: Joachim Wagner, Leuphana University, Scharnhorststr. 1, C4.204 21335 Lüneburg, Phone: +49.4131.677-2330, Fax +49.4131.677-2026, e-mail:wagner@leuphana.de the relationship is decreasing at the left hand side of the interval and/or is increasing at the right hand side (resp. the opposite in case of an inverted $U$ shape). Lind and Mehlum (2010) adopt a general framework developed by Sasabuchi (1980) to test for the presence of a Ushaped or inverted U-shaped pattern and propose the Fieller (1954) method to compute the confidence interval for the estimated extreme value.

The insights provided by Lind and Mehlum (2010) cast some doubt on a well-known finding by David Blanchflower, which is set to become a stylised fact in the empirical literature on union membership. Blanchflower (2007, p. 1) claims to have found "an empirical regularity not hitherto identified, namely, the probability of being unionized follows an inverted U-shaped pattern in age, maximizing in the mid- to late 40 s in 34 of the 38 countries [studied]" (Blanchflower 2007, p. 1). To test for this pattern and compute the estimated maximum, Blanchflower estimates probit functions with a union membership dummy as the endogenous 

Table 1. Descriptive statistics on union membership and age in West Germany, 1980 - 2006

\begin{tabular}{|c|c|c|c|c|c|c|}
\hline \multirow[t]{2}{*}{ Sample } & \multicolumn{2}{|c|}{$1980-1988$} & \multicolumn{2}{|c|}{$1990-1998$} & \multicolumn{2}{|c|}{$2000-2006$} \\
\hline & $\begin{array}{l}\text { Share } \\
\text { (per cent) }\end{array}$ & $\begin{array}{l}\text { Age (mean) } \\
\text { (years) }\end{array}$ & $\begin{array}{l}\text { Share } \\
\text { (per cent) }\end{array}$ & $\begin{array}{l}\text { Age (mean) } \\
\text { (years) }\end{array}$ & $\begin{array}{l}\text { Share } \\
\text { (per cent) }\end{array}$ & $\begin{array}{l}\text { Age (mean) } \\
\text { (years) }\end{array}$ \\
\hline \multicolumn{7}{|l|}{ Men } \\
\hline Union members & 38.0 & 40.7 & 34.2 & 40.8 & 26.6 & 42.9 \\
\hline Non-members & 62.0 & 39.1 & 65.8 & 39.1 & 73.4 & 40.4 \\
\hline \multicolumn{7}{|l|}{ Women } \\
\hline Union members & 19.0 & 36.6 & 18.9 & 39.8 & 16.5 & 42.0 \\
\hline Non-members & 81.0 & 36.7 & 81.1 & 37.9 & 83.5 & 40.5 \\
\hline
\end{tabular}

Note: Computed from various waves of the ALLBUS survey; see text for details.

pleted apprenticeship or master craftsman, polytech or university degree, blue-collar worker, civil servant, public sector employee, and father being a blue collar worker as well as the value of an index measuring the political orientation of individuals from $1=$ extreme left to $10=$ extreme right. (See Schnabel \& Wagner $(2005 ; 2008)$ for a discussion of these control variables, which are standard in the unionisation literature.)

We test the Blanchflower (2007) hypothesis of an inverted U-shaped pattern of union membership in age with a maximum at the mid- to late $40 \mathrm{~s}$ in three stages. First, we apply the standard significance tests to the estimated coefficients of the variables age and age squared (both separately and jointly). Second, we conduct a Sasabuchi (1980) test of an inverted U-shape in age (also known as an intersection-union test), which tests the composite null hypothesis that the relationship is increasing at low values of the age interval, decreasing at high values, or both. Third, for the estimated extreme point, we compute the Fieller (1954) confidence interval (for the ratio of the two normally distributed estimates for the age and age squared variables) and determine whether this confidence interval is contained within the data range. We also observe whether the estimated maximum lies in the age range found by Blanchflower - i.e., the mid- to late 40s (for details regarding the statistical theory underlying these methods, see Lind and Mehlum (2010). All computations use Stata 10.0 and the ado-file utest provided by Lind and Mehlum. To facilitate replication and extensions all do-files are available from the second author.

\section{Empirical results}

The results of our empirical investigation for men and women are reported in Tables $2.1-2.3$ and Tables $3.1-3.3$, respectively. Given our focus on testing the inverted U-shape hypothesis, we report only the estimated coefficients of the age and age squared variables - that is, we do not report the coefficients of the cohort dummy variables, the survey dummy variables, and the control variables measured at the individual level (while not reported here, detailed results for the individual-level control variables are available from the second author).

Our results concerning men clearly reject the hypothesis of an inverted U-shaped pattern of union membership in age with a maximum at the mid- to late 40 s. While age (age squared) has a positive (negative) sign in all 12 empirical models, the estimated coefficients are only separately and jointly statistically significant at an error level of five per cent or less in model 1 for all three decades and model 4 for the pooled data from 1990 to 1998 . This weak evidence, however, is contrasted by the Sasabuchi test, which rejects the hypothesis at the five per cent level for all of the models except model 4 in the 1990s. Even in this model, however, a closer look casts doubt on the second part of the hypothesis concerning the maximum. The Fieller confidence interval is rather broad, spanning an age period from the late 20 s to the mid50s. Thus, we find no stable evidence of a Blanchflower-type relationship between unionisation and age among West German men. 
Table 2-1. Test of an inverse U-shaped relationship between the probability of union membership and age for West German men. Part I: 1980 - 1988

\begin{tabular}{|c|c|c|c|c|c|}
\hline & & Model 1 & Model 2 & Model 3 & Model 4 \\
\hline \multirow{2}{*}{ Age (years) } & $\beta$ & 0.04076 & 0.03092 & 0.02578 & 0.02205 \\
\hline & $\mathrm{p}$ & 0.008 & 0.248 & 0.347 & 0.480 \\
\hline \multirow{2}{*}{ Age squared } & B & -0.00040 & -0.00032 & -0.00030 & -0.00027 \\
\hline & $p$ & 0.032 & 0.323 & 0.348 & 0.459 \\
\hline Test of joint significance of age variables. prob-value & & 0.0001 & 0.431 & 0.635 & 0.760 \\
\hline Sasabuchi-test of inverse U-shape in age. prob-value & & 0.114 & 0.276 & 0.232 & 0.264 \\
\hline Estimated extreme point (years) (bounds of 95\% Fieller interval) & & $\begin{array}{l}50.5 \\
{[44.3 ; 154.7]}\end{array}$ & $\begin{array}{l}48.8 \\
\text { [-inf.; +inf.] }\end{array}$ & $\begin{array}{l}42.8 \\
\text { [-inf.; +inf.] }\end{array}$ & $\begin{array}{l}40.3 \\
\text { [-inf.; +inf.] }\end{array}$ \\
\hline Test of joint significance of cohort dummy variables. prob-value & & {$[-]$} & 0.004 & 0.0025 & 0.054 \\
\hline Test of joint significance of survey dummy variables. prob-value & & {$[-]$} & {$[-]$} & 0.145 & 0.338 \\
\hline Test of joint significance of control variables. prob-value & & {$[-]$} & {$[-]$} & {$[-]$} & 0.000 \\
\hline LR-test of entire regression prob-value & & 0.0001 & 0.0000 & 0.0000 & 0.0000 \\
\hline Number of observations & & 2943 & 2943 & 2943 & 2234 \\
\hline
\end{tabular}

Notes: $\boldsymbol{B}$ is the estimated regression coefficient from a probit model; $\mathrm{p}$ is the prob-value (based on robust standard errors). For an explanation of the Sasabuchi-test and the Fieller interval, see text.

Cohort dummy variables are included for birth years 1926-1935, 1936-1945, 1946-1955, 1956-1965, and 1966-1975, using 1916-1925 as the reference category. Survey dummy variables are included for the ALLBUS surveys 1982, 1986, and 1988, using 1980 as the reference category. The control variables include dummy variables for completed apprenticeship or master craftsman, polytech or university degree, blue-collar worker, civil servant, public sector employee, and father being a blue-collar worker, and the value of an index measuring political orientation (from $1=$ extreme left to $10=$ extreme right). Data from the ALLBUS survey for 1984 were excluded due to missing information on political orientation. [-] indicates that the group of variables is not included in the model.

Table 2-2. Test of an inverse U-shaped relationship between the probability of union membership and age for West German men. Part II: 1990 - 1998

\begin{tabular}{|c|c|c|c|c|c|}
\hline & & Model 1 & Model 2 & Model 3 & Model 4 \\
\hline \multirow{3}{*}{ Age (years) } & B & 0.04833 & 0.03262 & 0.03906 & 0.08597 \\
\hline & $\mathrm{p}$ & 0.004 & 0.241 & 0.170 & 0.009 \\
\hline & B & -0.00049 & -0.00050 & -0.00045 & -0.00107 \\
\hline Age squared & $p$ & 0.015 & 0.140 & 0.185 & 0.008 \\
\hline Test of joint significance of age variables. prob-value & & 0.000 & 0.176 & 0.388 & 0.028 \\
\hline Sasabuchi-test of inverse U-shape in age. prob-value & & 0.067 & 0.183 & 0.164 & 0.011 \\
\hline Estimated extreme point (years) (bounds of 95\% Fieller interval) & & $\begin{array}{l}49.3 \\
{[44.2 ; 86.5]}\end{array}$ & $\begin{array}{l}32.8 \\
\text { [-inf.; +inf.] }\end{array}$ & $\begin{array}{l}43.8 \\
\text { [-inf.; +inf.] }\end{array}$ & $\begin{array}{l}40.2 \\
{[27.5 ; 55.2]}\end{array}$ \\
\hline Test of joint significance of cohort dummy variables. prob-value & & {$[-]$} & 0.133 & 0.965 & 0.670 \\
\hline Test of joint significance of survey dummy variables. prob-value & & {$[-]$} & {$[-]$} & 0.114 & 0.241 \\
\hline Test of joint significance of control variables. prob-value & & {$[-]$} & {$[-]$} & {$[-]$} & 0.0000 \\
\hline LR-test of entire regression prob-value & & 0.0000 & 0.0002 & 0.0002 & 0.0000 \\
\hline Number of observations & & 2907 & 2907 & 2907 & 2320 \\
\hline
\end{tabular}

Notes: $\beta$ is the estimated regression coefficient from a probit model; $p$ is the prob-value (based on robust standard errors). For an explanation of the Sasabuchi-test and the Fieller interval, see text.

Cohort dummy variables are included for birth years 1926-1935, 1936-1945, 1946-1955, 1956-1965, and 1966-1975, using 1916-1925 as the reference category. Survey dummy variables are included for the ALLBUS surveys 1992, 1994, 1996, and 1998, using 1990 as the reference category. The control variables include dummy variables for completed apprenticeship or master craftsman, polytech or university degree, blue-collar worker, civil servant, public sector employee, and father being a blue collar worker, and the value of an index measuring political orientation (from $1=$ extreme left to 10 = extreme right). [-] indicates that the group of variables is not included in the model. 
Table 2-3. Test of an inverse U-shaped relationship between the probability of union membership and age for West German men. Part III: 2000 - 2006

\begin{tabular}{|c|c|c|c|c|c|}
\hline & & Model 1 & Model 2 & Model 3 & Model 4 \\
\hline \multirow{2}{*}{ Age (years) } & B & 0.06930 & 0.00042 & 0.00996 & 0.01514 \\
\hline & p & 0.003 & 0.993 & 0.831 & 0.779 \\
\hline \multirow{2}{*}{ Age squared } & ß & -0.00067 & -0.00012 & -0.00008 & -0.00010 \\
\hline & $p$ & 0.016 & 0.819 & 0.875 & 0.872 \\
\hline Test of joint significance of age variables. prob-value & & 0.000 & 0.580 & 0.962 & 0.786 \\
\hline Sasabuchi-test of inverse U-shape in age. prob-value & & 0.104 & 1.000 & 0.487 & 1.000 \\
\hline Estimated extreme point (years) (bounds of 95\% Fieller interval) & & $\begin{array}{l}52.0 \\
{[46.1 ; 98.2]}\end{array}$ & $\begin{array}{l}1.7 \\
{[- \text { inf.; +inf.] }}\end{array}$ & $\begin{array}{l}58.7 \\
{[-i n f . ;+i n f .]}\end{array}$ & $\begin{array}{l}75.6 \\
\text { [-inf.; +inf.] }\end{array}$ \\
\hline Test of joint significance of cohort dummy variables. prob-value & & {$[-]$} & 0.0015 & 0.008 & 0.411 \\
\hline Test of joint significance of survey dummy variables. prob-value & & {$[-]$} & {$[-]$} & 0.243 & 0.397 \\
\hline Test of joint significance of control variables. prob-value & & {$[-]$} & {$[-]$} & {$[-]$} & 0.000 \\
\hline LR-test of entire regression prob-value & & 0.0000 & 0.0000 & 0.0000 & 0.0000 \\
\hline Number of observations & & 1708 & 1708 & 1708 & 1410 \\
\hline
\end{tabular}

Notes: $B$ is the estimated regression coefficient from a probit model; $p$ is the prob-value (based on robust standard errors). For an explanation of the Sasabuchi-test and the Fieller interval, see text.

Cohort dummy variables are included for birth years 1946-1955, 1956-1965, 1966-1975, and 1976-1985, using 1936-1945 as the reference category. Survey dummy variables are included for the ALLBUS surveys 2002 and 2004, using 2000 as the reference category. The control variables include dummy variables for completed apprenticeship or master craftsman, polytech or university degree, blue-collar worker, civil servant, public sector employee, and father being a blue collar worker, and the value of an index measuring political orientation (from $1=$ extreme left to $10=$ extreme right). [-] indicates that the group of variables is not included in the model.

Table 3-1. Test of an inverse U-shaped relationship between the probability of union membership and age for West German women. Part I: 1980 - 1988

\begin{tabular}{|c|c|c|c|c|c|}
\hline & & Model 1 & Model 2 & Model 3 & Model 4 \\
\hline \multirow{2}{*}{ Age (years) } & ß & -0.015 & -0.0126 & -0.0095 & -0.0172 \\
\hline & $p$ & 0.478 & 0.737 & 0.807 & 0.709 \\
\hline \multirow{2}{*}{ Age squared } & B & 0.00019 & -0.00009 & -0.00011 & 0.0002 \\
\hline & $p$ & 0.490 & 0.848 & 0.819 & 0.714 \\
\hline Test of joint significance of age variables. prob-value & & 0.7745 & 0.1126 & 0.3816 & 0.9316 \\
\hline Sasabuchi-test of inverse U-shape in age. prob-value & & 0.262 & 1.000 & 1.000 & 0.389 \\
\hline Estimated extreme point (years) (bounds of 95\% Fieller interval) & & $\begin{array}{l}40.0 \\
{[- \text { inf .; +inf.] }}\end{array}$ & $\begin{array}{l}-68.5 \\
\text { [-inf.; 35.2] }\end{array}$ & $\begin{array}{l}-43.2 \\
{[- \text { inf.; +inf.] }}\end{array}$ & $\begin{array}{l}41.2 \\
\text { [-inf.; +inf.] }\end{array}$ \\
\hline Test of joint significance of cohort dummy variables. prob-value & & {$[-]$} & 0.1300 & 0.3751 & 0.4519 \\
\hline Test of joint significance of survey dummy variables. prob-value & & {$[-]$} & {$[-]$} & 0.8258 & 0.6926 \\
\hline Test of joint significance of control variables. prob-value & & {$[-]$} & {$[-]$} & {$[-]$} & 0.0000 \\
\hline LR-test of entire regression prob-value & & 0.7745 & 0.2492 & 0.4466 & 0.0000 \\
\hline Number of observations & & 1767 & 1767 & 1767 & 1323 \\
\hline
\end{tabular}

Notes: $B$ is the estimated regression coefficient from a probit model; $p$ is the prob-value (based on robust standard errors). For an explanation of the Sasabuchi-test and the Fieller interval, see text.

Cohort dummy variables are included for birth years 1926-1935, 1936-1945, 1946-1955, 1956-1965, and 1966-1975, using 1916-1925 as the reference category. Survey dummy variables are included for the ALLBUS surveys 1982, 1986, and 1988, using 1980 as the reference category. The control variables include dummy variables for completed apprenticeship or master craftsman, polytech or university degree, blue-collar worker, civil servant, public sector employee, and father being a blue-collar worker, and the value of an index measuring the political orientation (from $1=$ extreme left to 10 = extreme right). Data from the ALLBUS survey for 1984 were excluded due to missing information on political orientation. [-] indicates that the group of variables is not included in the model. 
Table 3-2. Test of an inverse U-shaped relationship between the probability of union membership and age for West German women. Part II: 1990 - 1998

\begin{tabular}{|c|c|c|c|c|c|}
\hline & & Model 1 & Model 2 & Model 3 & Model 4 \\
\hline \multirow{2}{*}{ Age (years) } & B & 0.0544 & 0.0494 & 0.0595 & 0.0649 \\
\hline & $p$ & 0.020 & 0.215 & 0.134 & 0.180 \\
\hline \multirow{2}{*}{ Age squared } & B & -0.0006 & -0.00062 & -0.00062 & -0.00071 \\
\hline & $\mathrm{p}$ & 0.049 & 0.197 & 0.198 & 0.236 \\
\hline Test of joint significance of age variables. prob-value & & 0.0028 & 0.4340 & 0.2947 & 0.3885 \\
\hline Sasabuchi-test of inverse U-shape in age. prob-value & & 0.0947 & 0.123 & 0.233 & 0.218 \\
\hline \multirow{2}{*}{\multicolumn{2}{|c|}{ Estimated extreme point (years) (bounds of 95\% Fieller interval) }} & 47.6 & 39.6 & 48.4 & 45.4 \\
\hline & & {$[41.9 ; 1564.1]$} & [-inf.; +inf.] & [-inf.; +inf.] & [-inf.; +inf.] \\
\hline Test of joint significance of cohort dummy variables. prob-value & & {$[-]$} & 0.2988 & 0.3681 & 0.7734 \\
\hline Test of joint significance of survey dummy variables. prob-value & & {$[-]$} & {$[-]$} & 0.2326 & 0.1833 \\
\hline Test of joint significance of control variables. prob-value & & {$[-]$} & {$[-]$} & {$[-]$} & 0.0000 \\
\hline LR-test of entire regression prob-value & & 0.0028 & 0.0106 & 0.0107 & 0.0000 \\
\hline Number of observations & & 1950 & 1950 & 1950 & 1492 \\
\hline
\end{tabular}

Notes: $B$ is the estimated regression coefficient from a probit model; $p$ is the prob-value (based on robust standard errors). For an explanation of the Sasabuchi-test and the Fieller interval, see text.

Cohort dummy variables are included for birth years 1926-1935, 1936-1945, 1946-1955, 1956-1965, and 1966-1975, using 1916-1925 as the reference category. Survey dummy variables are included for the ALLBUS surveys 1992, 1994, 1996, and 1998, using 1990 as the reference category. The control variables include dummy variables for completed apprenticeship or master craftsman, polytech or university degree, blue-collar worker, civil servant, public sector employee, and father being a blue collar worker, and the value of an index measuring political orientation (from $1=$ extreme left to 10 $=$ extreme right). [-] indicates that the group of variables is not included in the model.

Table 3-3. Test of an inverse U-shaped relationship between the probability of union membership and age for West German women. Part III: 2000 - 2006

\begin{tabular}{|c|c|c|c|c|c|}
\hline & & Model 1 & Model 2 & Model 3 & Model 4 \\
\hline \multirow{2}{*}{ Age (years) } & ß & 0.0738 & 0.0224 & 0.0407 & 0.0920 \\
\hline & $\mathrm{p}$ & 0.013 & 0.692 & 0.488 & 0.186 \\
\hline \multirow{2}{*}{ Age squared } & B & -0.00081 & -0.00043 & -0.000383 & -0.00088 \\
\hline & $\mathrm{p}$ & 0.024 & 0.523 & 0.577 & 0.288 \\
\hline Test of joint significance of age variables. prob-value & & 0.0179 & 0.4489 & 0.7183 & 0.2970 \\
\hline Sasabuchi-test of inverse U-shape in age. prob-value & & 0.039 & 0.417 & 0.405 & 0.312 \\
\hline Estimated extreme point (years) (bounds of 95\% Fieller interval) & & $\begin{array}{l}45.7 \\
{[40.7 ; 78.0]}\end{array}$ & $\begin{array}{l}26.1 \\
\text { [-inf.; +inf.] }\end{array}$ & $\begin{array}{l}53.1 \\
\text { [-inf.; +inf.] }\end{array}$ & $\begin{array}{l}52.0 \\
{[\text {-inf.; +inf. }]}\end{array}$ \\
\hline Test of joint significance of cohort dummy variables. prob-value & & {$[-]$} & 0.0424 & 0.1143 & 0.1392 \\
\hline Test of joint significance of survey dummy variables. prob-value & & {$[-]$} & {$[-]$} & 0.0199 & 0.0802 \\
\hline Test of joint significance of control variables. prob-value & & {$[-]$} & {$[-]$} & {$[-]$} & 0.0000 \\
\hline LR-test of entire regression prob-value & & 0.0179 & 0.0044 & 0.0008 & 0.0000 \\
\hline Number of observations & & 1309 & 1309 & 1309 & 1058 \\
\hline
\end{tabular}

Notes: $B$ is the estimated regression coefficient from a probit model; $p$ is the prob-value (based on robust standard errors). For an explanation of the Sasabuchi-test and the Fieller interval, see text.

Cohort dummy variables are included for birth years 1946-1955, 1956-1965, 1966-1975, and 1976-1985, using 1936-1945 as the reference category. Survey dummy variables are included for the ALLBUS surveys 2002 and 2004, using 2000 as the reference category. The control variables include dummy variables for completed apprenticeship or master craftsman, polytech or university degree, blue-collar worker, civil servant, public sector employee, and father being a blue collar worker, and the value of an index measuring political orientation (from $1=$ extreme left to $10=$ extreme right). [-] indicates that the group of variables is not included in the model. 
The results for West German women are even less consistent with Blanchflower's hypothesis. The estimated coefficients of the age and age squared variables are only individually and jointly statistically significantly different from zero at an error level of five per cent or better for model 1 in the 1990s and 2000s. Only the latter model also passes the Sasabuchi test with a probvalue of 0.039 . While the point estimates of the maximum are consistent with Blanchflower's hypothesis in both cases (taking values of 47.6 and 45.7 years), the Fieller confidence intervals demonstrate that these estimates are too imprecise to establish that the maximum falls within the range of the mid- to late 40 s.

\section{Concluding remarks}

The results presented in this note cast some doubt on the claim proposed by David Blanchflower (2007) that the probability of unionisation follows an inverted $\mathrm{U}$ shaped pattern in age with a maximum in the mid-to late 40s. In contrast to the findings Blanchflower (2007) presents concerning Germany, we demonstrate that at least with respect to West Germany - this is not the case. Because our findings are based on a different data set than Blanchflower's, distinguish between men and women, and, for the first time in this context, apply Lind and Mehlum's (2010) statistical method, which is best suited for testing U-shaped patterns, by Lind and Mehlum (2010) that has not been used before in this context, we would agree that the jury is still out on the relationship between union membership and age.

\section{References}

Blanchflower, D. G. (2007). International Patterns of Union Membership. British Journal of Industrial Relations, 45(1), 1-28.

Fieller, E. C. (1954). Some problems in interval estimation. Journal of the Royal Statistical Society, Series $B, 16(2), 175-185$.

Lind, J. T. \& Mehlum, H. (2010). With or Without U? - The Appropriate Test for a U-Shaped Relationship. Oxford Bulletin of Economics and Statistics, 72(1), 109-118.

Terwey, M. (2000). ALLBUS: A German General Social Survey. Schmollers Jahrbuch / Journal of Applied Social Science Studies, 120(1), 151-158.

Sasabuchi, S. (1980). A test of a multivariate normal mean with composite hypotheses determined by linear inequalities. Biometrika, 67(2), 429-439.
Schnabel, C. \& Wagner, J. (2005). Determinants of trade union membership in West Germany: evidence from micro data, 1980-2000. Socio-Economic Review, 3(1), 1-24.

Schnabel, C. \& Wagner, J. (2008). The Aging of the Unions in West Germany, 1980-2006. Jahrbücher für Nationalökonomie und Statistik / Journal of Economics and Statistics, 228(5-6), 497-511.

\section{Acknowledgements}

\author{
This paper uses data from various ALLBUS surveys \\ provided by the Zentralarchiv für Empirische Sozialforsc- \\ hung in Cologne. The authors alone are responsible for \\ the use of the data in this study and for any conclusions \\ drawn here.
}




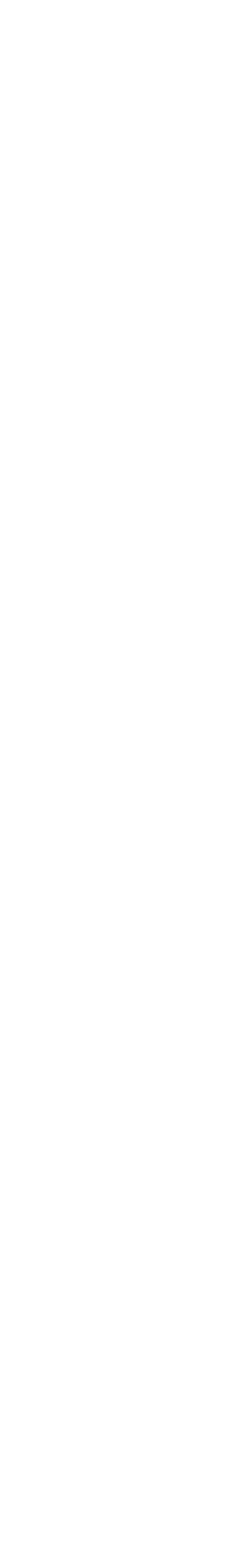

(n)

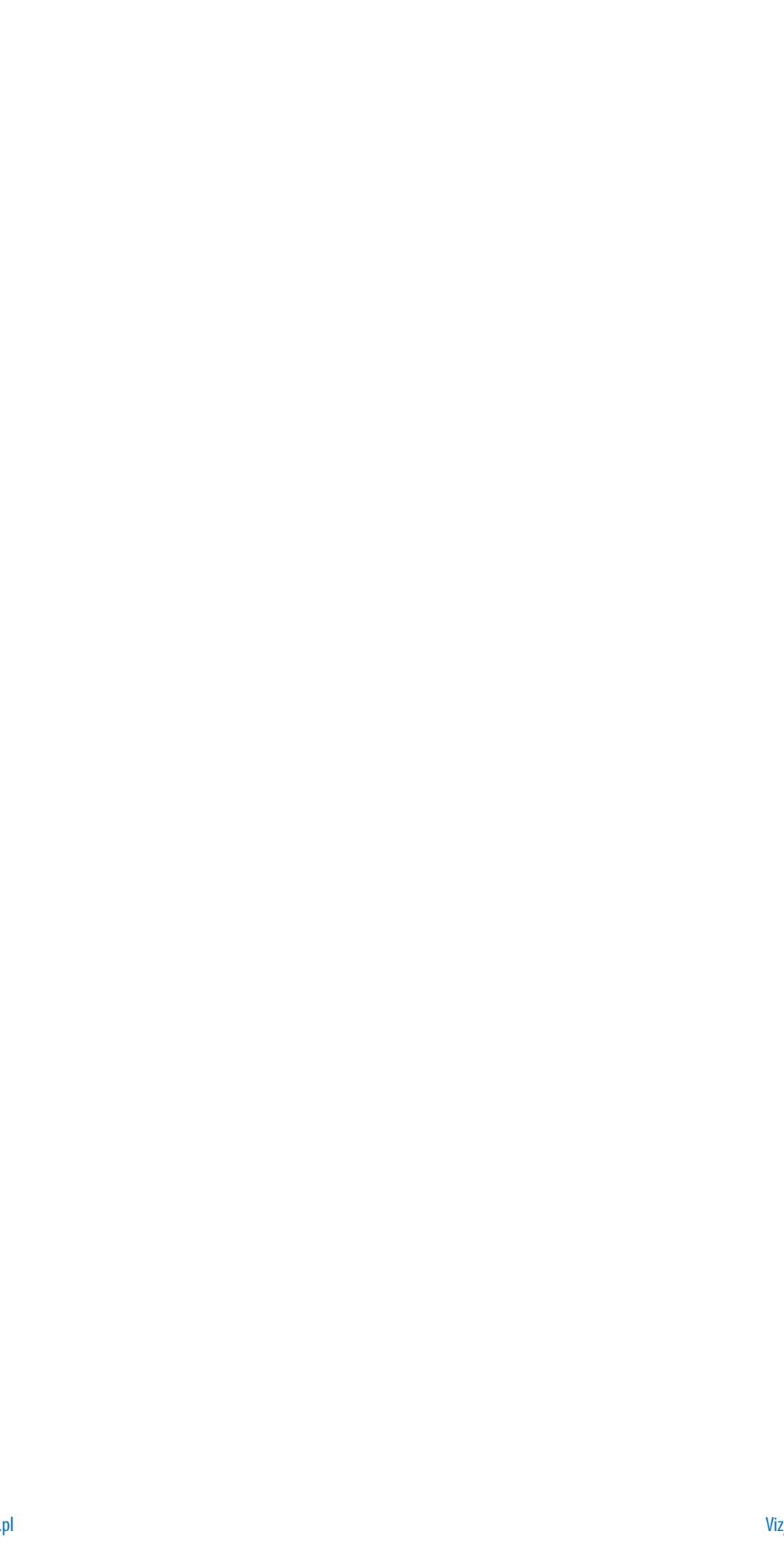

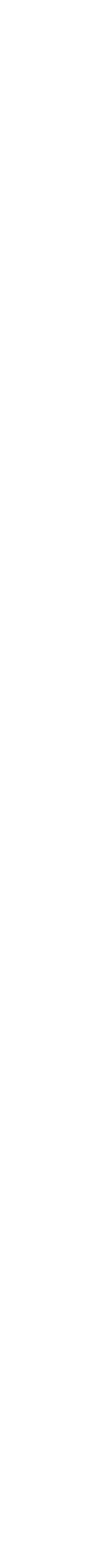

